\title{
Efficacy of lidocaine-prilocaine combination cream in reducing pain caused by hepatitis $B$ injection in neonates: a randomized control trial
}

\author{
Nugroho Karyadiguna, Soetjiningsih, W. Retayasa, M. Kardana
}

\begin{abstract}
Background Many invasive medical procedures cause pain in neonates. Pain in this age group increases morbidity, impairs emotional bonding, and causes hyperalgesia. Combination of lidocaine and prilocaine cream is one of the topical analgesics that are easy to use and safe for neonates.

Objective To assess the efficacy of lidocaine-prilocaine combination cream in reducing pain caused by intramuscular injection of hepatitis B and to find out the correlation of sex, gestational age, birth weight, chronological age, and method of delivery with infant's pain response.

Methods A double blind randomized controlled trial was conducted on term neonates. Subjects were selected consecutively and every subject was randomized to either receive lidocaineprilocaine cream or placebo one hour prior to administration of intramuscular hepatitis B vaccine. The administration was recorded by a handycam and the intensity of pain responses was evaluated using DAN (Douleur Aigue Nouveau-ne) scale.

Results Of 67 subjects, the mean of DAN scale was 7.60 (95\% CI $7.27 ; 7.95)$ in the lidocaine-prilocaine cream group and this was significantly lower $(\mathrm{P}<0.0001)$ than in placebo group, which was $8.82(95 \%$ CI 8.56;9.09). ANCOVA showed that there were no associations between sex, gestational age, birth weight, chronological age, and method of delivery with infant's pain response.

Conclusion Lidocaine-prilocaine combination cream can reduce the pain caused by intramuscular injection of hepatitis $B$ vaccine on term neonates. [Paediatr Indones 2007;47:12-16].
\end{abstract}

Keywords: lidocaine-prilocaine cream, pain, neonates
7 here are many invasive medical procedures during infancy. An infant will have at least 7 injected immunizations before the age of
6 months. ${ }^{1}$ Unfortunately, many medical practitioners think that neonates are unable to feel pain or at least have high pain threshold because of their immature nervous systems. As a result, many of them do nothing to reduce the pain. ${ }^{2}$

Pain sensation is conducted by nervous system with specific sensory receptors called nociceptors. The impulse does not automatically produce pain sensation since pain perception is formulated by the brain. ${ }^{3}$ Nociceptors density in term neonates is similar to that in adults. ${ }^{4,5}$ Pain will cause irritability, change in sleep pattern, high catabolism, and delay in ability to make emotional bonding even memory of pain. ${ }^{6}$ Because pain is a subjective sensation, the best pain assessment is through self report method. However, it depends on patient's ability to report the location, quality, intensity and tolerability of pain

From the Department of Child Health, Medical School, Udayana University, Denpasar, Indonesia.

Reprint request to: Nugroho Karyadiguna, MD, Department of Child Health, Udayana University, Sanglah Hospital, Jl. P. Nias, Denpasar, Indonesia. Telp/Fax: 62-361-244038/257387/227911-15 ext 128. Email: ika_unud@yahoo.com. 
Karyadiguna Nugroho et al: Effect of lidocaine and prilocaine cream to reduce pain in hepatitis B immunization

which is difficult for children less than 3 years old. ${ }^{7}$ To assess pain in younger children or infants, some tools are required. One of the commonly used tool is Douleur Aigue Nouveau-ne (DAN) scale which assesses subjects' facial expressions, limb movement and vocal expression. ${ }^{8}$ This scale has been proven to have a good interrater reliability and internal consistency. ${ }^{9}$

Lidocaine-prilocaine combination cream is a topical anesthetic agent which can be absorbed through intact skin. This cream has been used to reduce pain caused by medical procedures such as venipuncture, skin cauterization and circumcision. This cream has also been proven to be safe for neonates. ${ }^{10,11}$ This study assessed the efficacy of lidocaine-prilocaine combination cream in reducing pain caused by intramuscular injection of hepatitis B. This study also aimed to find out the association between sex, gestational age, birth weight, infant's chronological age, method of delivery and infant's pain response.

\section{Methods}

This study was a double blind randomized controlled trial conducted at the neonatal ward of Sanglah Hospital, Department of Child Health, Medical School, Udayana University, Denpasar, Bali from January until February 2006. This study has been approved by the Ethical Comittee of Research and Development Department of Sanglah Hospital. The nature and purpose of this study were explained to parents and informed consent was obtained.

We included term neonates, which is appropriate for gestational age and born in Sanglah Hospital. Infants with Apgar scores $<7$ at the first or fifth minute of life, those with major congenital anomaly, severe illness, requiring oxygen, requiring any invasive procedure, or born using forceps or vacuum or need any therapy beyond routine treatment for healthy neonates were excluded.

Subjects were recruited consecutively, and each was randomized using a random number table; subject's assignment was put in a sealed envelope. Neonates enrolled in this study received routine newborn care and oral vitamin $\mathrm{K}$. Prior to discharge, all subjects received intramuscular hepatitis B immunization. One hour prior to injection, every subject received \pm 0.5 gram lidocaine-prilocaine cream or placebo cream on a $4 \mathrm{~cm}^{2}(2 \mathrm{~cm} \times 2 \mathrm{~cm})$ area of right thigh and covered with an occlusive dressing. After these procedures, neonates were put on fasting and not to be given any pacifier. Occlusive dressings were removed prior to the immunization and the injection area was cleaned with $70 \%$ alcohol. Subjects must be calm before the injection. The video recording was started a few seconds prior to injection until the subjects were calm after the injection.

Subjects received injection on supine position and maintained in that position until the video recording was stopped. The needle was injected perpendicular until the whole needle was inside subject's thigh ( $2 / 3$ inch needle). The lidocaineprilocaine combination cream (TOPSY ${ }^{\circledR}$ ) and the placebo cream were provided by PT. Galenium Pharmasia Laboratories with the same color, odor, and packaging. Hepatitis B vaccine used in this study was a prefilled recombinant vaccine produced by PT. Bio Farma.

Pain was assessed using DAN scale by two senior pediatric residents from Udayana University who were not involved in any part of this study (except being the examiner of the video) on two separate occasions, independent and blinded from the treatment of the subjects. There was a linear relationship with a relatively strong correlation $(r=0.68 ; \mathrm{P}<0.0001)$ between the two examiners.

We used Kolmogorov-Smirnov test and ANCOVA multivariate analyses by computer statistical software.

\section{Results}

Sixty-seven neonates were enrolled in this study, 33 of them were included in the lidocaine-prilocaine group while the rests were in the placebo group. The baseline characteristics of both groups were similar at the beginning of the study (Table 1).

Mean DAN scale for the treatment group was $7.60(95 \%$ CI $7.27 ; 7.95)$ compared to 8.82 (95\%CI $8.56 ; 9.09$ ) for the placebo group (Figure 1). Based on this result, the DAN scale for the treatment group was significantly lower with $\mathrm{P}<0.0001$ and mean difference of $-1.2175(95 \% \mathrm{CI}-1.64 ;-0.79)$. 
Karyadiguna Nugroho et al: Effect of lidocaine and prilocaine cream to reduce pain in hepatitis B immunization

Table 1. Baseline characteristics of the subjects

\begin{tabular}{lcc}
\hline & $\begin{array}{c}\text { Lidocaine-prilocaine } \\
(\mathrm{n}=33)\end{array}$ & $\begin{array}{c}\text { Placebo } \\
(\mathrm{n}=34)\end{array}$ \\
\hline $\begin{array}{l}\text { Sex, } \mathrm{n}(\%) \\
\quad \text { Male }\end{array}$ & 17 & 19 \\
APGAR & & \\
$\quad 1^{\text {st }}$ minute, mean(SD) & $7.36(0.55)$ & $7.35(0.49)$ \\
$\quad 5^{\text {th }}$ minute, mean (SD) & $8.27(0.52)$ & $8.29(0.58)$ \\
Birth weight (g), mean (SD) & $3062(318.9)$ & $3163(348.7)$ \\
Birth length (cm), mean (SD) & $48.7(1.4)$ & $49.3(1.3)$ \\
Gestational age (weeks), mean (SD) & $39.4(1.4)$ & $39.2(1.3)$ \\
Subject chronological age & & \\
when cream was applied (hour), mean (SD) & $21.7(8.8)$ & $22.18(11.2)$ \\
Method of delivery, $\mathrm{n}$ & & 30 \\
$\quad$ Spontaneous & 28 & 4 \\
$\quad$ Caesarean section & 5 & $26.9(5.7)$ \\
Mother's age (year), mean (SD) & $28.0(4.8)$ &
\end{tabular}

The only side effects found in this study was blanching of the skin on the contact area. Fourteen neonates vs. 2 neonates in treatment group and placebo group experience the blanching. There was a significant difference with $\mathrm{P}<0.0001$ and mean difference of $0.365(95 \% \mathrm{CI} 0.18 ; 0.56)$.

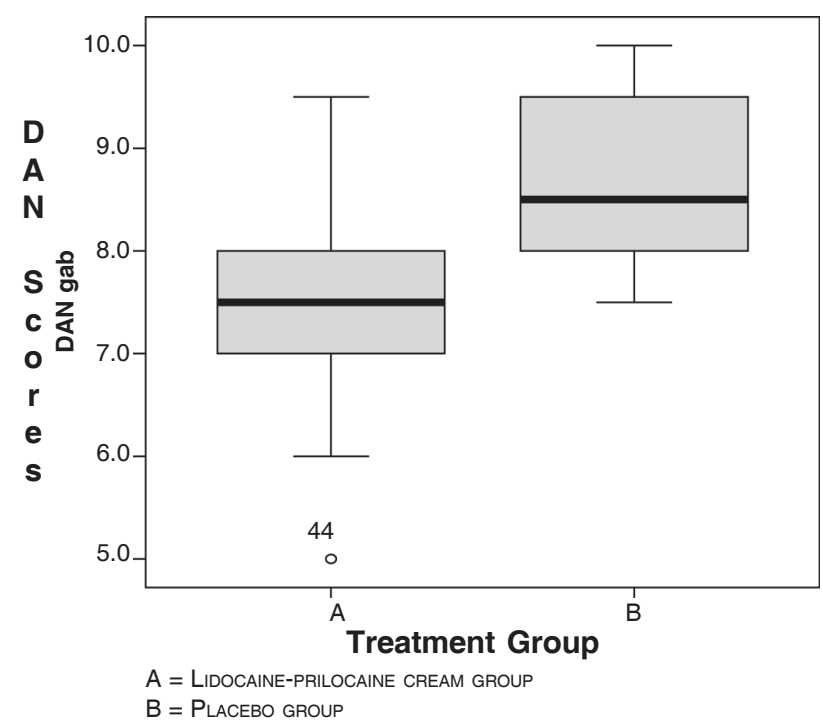

Figure 1. Box plot of the two different treatment groups.

Table 2. ANCOVA multivariate analysis on characteristics that may alter pain response

\begin{tabular}{lccc}
\hline Characteristics & Mean square & $\mathrm{F}$ & $\mathrm{P}$ \\
\hline Sex & 0.131 & 0.174 & 0.678 \\
Gestational age & 0.392 & 0.523 & 0.472 \\
Birth weight percentile & 0.963 & 1.286 & 0.261 \\
Subject chronological age & 2.116 & 2.828 & 0.098 \\
Method of delivery & 0.209 & 0.279 & 0.599 \\
Lidocaine-Prilocaine cream & 2.540 & 33.515 & 0.000 \\
\hline
\end{tabular}

Using ANCOVA multivariate analyses, we found that sex, gestational age, birth weight's percentiles (Lubchenco scale), neonate's age in hours, and method of delivery (spontaneous or Caesarean section) did not significantly alter pain response. Only lidocaine-prilocaine cream had a significant effect to reduce pain with $\mathrm{P}<0.0001$. The complete ANCOVA multivariate analysis is shown in Table 2.

\section{Discussion}

There are several double blind randomized studies using lidocaine-prilocaine combination cream in reducing pain caused by intramuscular injection. Most of those studies showed that lidocaineprilocaine cream is able to reduce the pain caused by intramuscular injection. The types of fluid that have been examined and published for intramuscular injections varied from normal saline to vaccine fluid, ${ }^{12,13}$ the types of given vaccine also varied from DPT in the study of Uhari ${ }^{4}$ until DTaP-IPV-Hibhepatitis B by Halperin et al. ${ }^{13}$

The age of subjects varied as well. In the study done by Uhari, ${ }^{4}$ subjects' age was between 3 months until 28 months. There were also some specific age groups of studies, such as the study done by Halperin et $a l^{13}$ on 6 -month-old infants and by Tadio et $\mathrm{al}^{13}$ on 12-month-old infants.

We found that lidocaine-prilocaine cream was able to reduce the pain caused by the intramuscular hepatitis $B$ vaccination on neonatal group with mean 
DAN score of 7.60 compared with 8.82 in placebo group. Compared to the studies mentioned above, the result of this study showed a similar result that there was a significant decreased in pain caused by intramuscular injection in the subjects who have been given lidocaine-prilocaine cream. However, we did not find other study using this cream to reduce the pain caused by intramuscular injection on neonatal age group. We also did not find any similar study done in Indonesia so this is the first one using lidocaineprilocaine cream in neonates.

We only found one study comparing lidocaineprilocaine cream to placebo where it was not able to reduce the pain caused by intramuscular injection. It was done by Hansen et $a^{13}$ using MMR vaccine on children at the age of 11 until 15 years. However, we should notice that the above study used a non- visual pain measurement with unknown validity and reliability. ${ }^{13}$

In this study, method of delivery had no significant influenced to pain expression. This finding might be explained by an insignificant difference on pain produced by spontaneous delivery and caesarean section. The pain expression was also not influenced by subject's age or gestational age. This indicates that the maturity of the nervous system among term neonates is not different significantly between 37 42 weeks of gestational age and post natal age. Singh et $\mathrm{al}^{14}$ found that preterm neonates with gestational age between 32-34 weeks had lesser changes in behavior as response to pain compared to neonates with gestational age $\geq 35$ weeks. However, they have similar physiologic changes (heart rate, respiratory rate, and oxygen saturation) in response to pain compared to the more mature neonates. The difference might be caused by lesser ability of premature neonates to move their extremities or their facial muscles. ${ }^{14}$ We were unable to find any studies that compare the effectiveness of lidocaineprilocaine cream between term and preterm neonates.

Lidocaine and prilocaine concentration had no significant effect to subject's pain expression. Sex also gave no significant effect to subject's pain expression. In adult, psychological and blood pressure factors gave significant contribution to alter pain response between these two sexes. ${ }^{15}$ However, among neonates, those factors might not appear yet.
The lidocaine-prilocaine cream can also be combined with other methods to reduce the pain caused by medical procedures. One method that has been published was done by Lindh et al. ${ }^{12}$ They combined this cream with oral glucose water. In that study, they found that the method was able to reduce the pain caused by intramuscular DPT injection compared to placebo. Unfortunately, we were unable to find any study comparing lidocaine-prilocaine cream alone with any combination method such as mentioned above.

Several of the most commonly reported non pharmacological methods to reduce pain in neonates are hugging the neonates, giving milk and using pacifier. ${ }^{16}$ Future studies to compare the effectiveness of those methods to lidocaine-prilocaine cream in reducing pain are needed.

We noted a significant side effect of lidocaineprilocaine cream, i.e., blanching of the skin on the side of cream application. This was caused by vasoconstrictor effect of the lidocaine-prilocaine cream and could last until 2 hours after the removal of the cream. ${ }^{17}$ We did not design this study to observe any delayed-type hypersensitivity (type IV) since this kind of hypersensitivity was rare for this cream. ${ }^{17}$ No difficulty in cream application was found in this study.

One of the study limitation was that we did no observation for physiologic and biochemical changes, due to the limitation of the available facility in Sanglah Hospital. We were also unable to control the room temperature which might cause environmental difference between one subject to another.

The time that is needed for lidocaine-prilocaine cream to achieve adequate anesthetic effect is the main obstacle for this cream to be used in daily practice, especially for immunization in outpatient clinic. However, it can be alleviated by giving good information to the parents about pain and the benefit of this cream. Moreover, since this cream is easy to be applied, we might also suggest the parents to apply this cream at home prior to their visit to the out patient clinic.

We concluded that lidocaine-prilocaine cream is able to reduce pain caused by intramuscular hepatitis $B$ vaccine injection. Sex, gestational age, birth weight percentile, chronological age, or method of delivery do not alter the pain expression. 
Karyadiguna Nugroho et al: Effect of lidocaine and prilocaine cream to reduce pain in hepatitis B immunization

\section{Acknowledgments}

We would like to express our highest gratitude to Dr. I Gde Raka Widiana, SpPD, KGH and Dr. Ida Bagus Subanada, SpA for their help in constructing methodology and statistical analyses in this study. We also would like to thank the nurses and the patients who participated in this study for making this study possible.

\section{Disclaimer}

This study was purely intended to study the effect of the lidocaine-prilocaine cream and not in any way interfered by PT. Galenium Pharmasia Laboratories even though the lidocaine-prilocaine cream and the placebo cream are provided by them.

\section{References}

1. Recommendation of Ikatan Dokter Anak Indonesia (IDAI) period of 2004. Cited in 2 December 2005. available from: url: http//www.idai.or.id/web/jadwal_imunisasi. html.

2. Porter FL, Wolf CM, Gold J, Lotsoff D, Miller JP. Pain and pain management in newborn infants: A survey of physician and nurses. Pediatrics 1997; 100:626-32.

3. Kandel ER, Schwartz JH, Jessel TM. Principles of neural science. 4th edition. New York: McGraw-Hill; 2000. p. 472-91.

4. Uhari M. A eutectic mixture of lidocaine and prilocaine for alleviating vaccination pain in infants. Pediatrics 1993; 92:917-21

5. Bursch B, Zelter LK. Pediatric pain management. In: Behrman RE, Kliegman RM, Jenson HB, editors. Nelson textbook of pediatrics. 17th ed. Philadelphia: Saunders; 2004. p. 358-66.
6. Mathew PJ, Mathew JL. Assessment and management of pain in infants. Postgrad Med J 2003;79:438-43.

7. American Academy of Pediatrics and American Pain Society. The assessment and management of acute pain in infants, children and adolescent. Pediatrics 2001;108:793-7.

8. Carbajal R, Chauvet X, Coudere S, Olivier-Martin M. Randomised trial of analgesic effects of sucrose, glucose, and pacifier in term neonates. BMJ 2003;319:1393-7.

9. Duhn LJ, Medves JM. A Systematic Integrative Review of Infant Pain Assessment Tools. Adv Neonatal Care 2004;4:126-40.

10. Tadio A, Stevens B, Craig K, Rastogi P, Ben-David S, Shennan A, et al. Efficacy and safety of lidocaineprilocaine cream for pain during circumcision. NEJM 1997;336:1197-201.

11. PDR drug information for EMLA cream. cited 2005 November 9. available from: url:http//www.drugs. com/pdr/ Emla_cream.html.

12. Lindh V, Wilkund U, Blomquist H, Hakansson S. EMLA cream and oral glucose for immunization pain in 3-monthold infants. Pain 2003;104:381-8.

13. Cassidy KL, Reid GJ, McGrath PJ, Smith DJ, Brown TL, Finley GA. A randomized double-blind, placebo-controlled trial of the EMLA patch for the reduction of pain associated with intramuscular injection in four to six-year-old children. Acta Paediatr 2001;90:1329-36.

14. Singh H, Singh D, Soni RK. Comparison of pain response to venipuncture between term and preterm neonates. Indian Paediatrics 2000;37:179-81.

15. Sheffield D, Biles PL, Orom H, Maixner W, Sheps DS. Race and sex differences in cutaneous pain perception. Psychosom Med;62:517-23.

16. Zempsky WT, Schechter NL. What's new in the management of pain in children. Pediatr Rev 2003;24:337-47.

17. Friedman MP, Mafong EA, Friedman ES, Geronemus RG. Topical anesthetics update: EMLA and beyond. Dermatol Surg 2001;27:1019-26. 